\title{
Structural Study of a Chemically Dealloyed Pt-Cu Oxygen Reduction Catalyst
}

\author{
I. Dutta*, M. P. Balogh**, M. K. Carpenter**, J. M. Ziegelbauer**, M. H. Atwan*, T. E. Moylan** \\ and N. P. Irish** \\ * Trison Business Solutions, GM Technical Center, Warren, MI \\ ** General Motors Research \& Development, Warren, MI
}

One of the major stumbling blocks to the commercialization of automotive fuel cells is the cost associated with the platinum catalysts. While platinum is used in both the anode and cathode, the cathode requires a substantially higher loading of platinum due to the sluggish kinetics of the oxygen reduction reaction (ORR) that occurs there. Although research and development over the years have resulted in significantly decreased platinum loading, recent economic calculations suggest that a further reduction by at least a factor of four must be realized if automotive fuel cells are to become commercially viable [1-2]. Early efforts to improve ORR activity explored the use of platinum alloys, but the reported activities of these materials were typically only two to three times that of a standard platinum catalyst [3-4]. Recently, several groups have reported promising catalyst systems. These include Pt monolayer catalysts on nanoparticles of other metals or metal combinations [5], dealloyed $\mathrm{Pt}$ alloy nanoparticle catalysts [6-7], and a $\mathrm{Pt}_{3} \mathrm{Ni}$ (111) single crystal face [8]. Common to all of these systems is a reactive Pt surface that is perturbed by a subsurface layer(s) of differing composition or structure. Clearly, subsurface characteristics such as composition, lattice mismatch, and lattice vacancies can affect surface properties such as Pt-Pt distance and electronic structure that are important for ORR activity. Thus to better understand these catalysts, it is important to probe both their surface and near-surface regions.

A carbon-supported, dealloyed platinum-copper $(\mathrm{Pt}-\mathrm{Cu})$ oxygen reduction catalyst was prepared using a multi-step synthetic procedure. Material produced at each step was characterized using high angle annular dark-field (HAADF) STEM (Cs-corrected JEOL 2100F TEM/STEM), electron energy loss spectroscopy (EELS) mapping (Gatan Tridium $\left.{ }^{\circledR}\right)$, x-ray absorption spectroscopy (XAS), x-ray diffraction (XRD); and its oxygen reduction reaction (ORR) activity was measured by a thin-film rotating disk electrode (TF-RDE) technique. The initial synthetic step, a co-reduction of metal salts, produced a range of poorly crystalline $\mathrm{Pt}, \mathrm{Cu}$, and $\mathrm{Pt}-\mathrm{Cu}$ nanoparticles that nevertheless exhibited good ORR activity as shown in Table 1.

Annealing this material alloyed the metals and increased particle size and crystallinity. TEM shows the annealed catalyst to include particles of various sizes, large $(>25 \mathrm{~nm})$, medium $(12-25 \mathrm{~nm})$, and small $(<12 \mathrm{~nm})$. Most of the small and medium-sized particles exhibited a partial or complete coreshell ( $\mathrm{Cu}$ rich core and $\mathrm{Pt}$ shell) structure, with the smaller particles typically having more complete shells (Fig. $1 \mathrm{a}$ and $\mathrm{b}$ ). The appearance of Pt shells after annealing indicates that they are formed by a thermal diffusion mechanism. Although the specific activity of the catalyst material was more than doubled by annealing, the concomitant decrease in Pt surface area resulted in a drop in its mass activity (Table 1).

Subsequent dealloying of the catalyst by acid treatment to partially remove the copper increased the Pt surface area by changing the morphology of the medium and large particles to a "Swiss-cheese" type structure having many voids as shown in Fig. $1 \mathrm{c}$. The smaller particles retained their core-shell structure (Fig. $1 \mathrm{~d}$ ). The specific activity of the catalyst material was little reduced by dealloying, but its mass activity was more than doubled due to the increase in surface area. Correlation of this 
chemical and structural information with electrochemical measurements can provide the basis for understanding the origin(s) of high activity in these catalysts.

\section{References}

1. H.A. Gasteiger et al., Appl. Catal. B-Environ., 56 (2005) 9.

2. B. James et al., Mass Production Cost Estimation for Direct $\mathrm{H}_{2}$ PEM Fuel Cell Systems for Automotive Applications, in DOE Hydrogen Program Review. 2008, Directed Technologies, Inc.

3. S. Mukerjee and S. Srinivasan, Journal of Electroanalytical Chemistry, 357 (1993) 201.

4. T. Toda et al., Journal of Electroanalytical Chemistry, 460 (1999) 258.

5. R.R. Adžić et al., Top. Catal., 46 (2007) 249.

6. S. Koh et al., Journal of The Electrochemical Society, 155 (2008) B1281.

7. S. Chen et al., Journal of The Electrochemical Society, 157 (2010) A82.

8. V.R. Stamenkovic et al., Science, 315 (2007) 493.

Table 1: Summary of PtCu catalyst composition, particle size and electrochemical properties.

\begin{tabular}{|c|c|c|c|c|c|c|c|}
\hline \multirow[b]{2}{*}{ Sample } & \multicolumn{2}{|c|}{ Composition } & \multirow{2}{*}{$\begin{array}{c}\text { Pt/cu } \\
\text { At. Ratio }\end{array}$} & \multirow{2}{*}{$\begin{array}{l}\text { Avg. Crystallite size } \\
(\mathrm{nm})[\mathrm{xrd}]\end{array}$} & \multirow{2}{*}{$\begin{array}{c}\text { ECSA } \\
\left(\mathrm{m}^{2} / \mathrm{g}_{\mathrm{pt}}\right)\end{array}$} & \multirow{2}{*}{$\begin{array}{c}\text { Mass activity } \\
\left(\mathrm{a} / \mathrm{mg}_{\mathrm{pt}} \text { at } 0.90 \mathrm{v}\right)\end{array}$} & \multirow{2}{*}{$\begin{array}{c}\text { Specific activity } \\
\left(\mu \mathrm{a} / \mathrm{cm}_{\mathrm{pt}}{ }^{2} \text { at } 0.90 \mathrm{v}\right)\end{array}$} \\
\hline & $\begin{array}{c}\text { Wt .\% } \\
\text { Pt }\end{array}$ & $\begin{array}{c}\text { Wt. \% } \\
\text { Cu }\end{array}$ & & & & & \\
\hline As-reduced & 20 & 20 & 0.3 & Broad peak & 70 & 0.21 & 300 \\
\hline Annealed & 22 & 23 & 0.3 & $F m \overline{3} m: 19 ; P m \overline{3} m: 21$ & 19 & 0.14 & 750 \\
\hline Dealloyed & 29 & 5.4 & 1.8 & $F m \overline{3} m: 12 ; F m \overline{3} m: 5.7$ & 50 & 0.29 & 580 \\
\hline
\end{tabular}
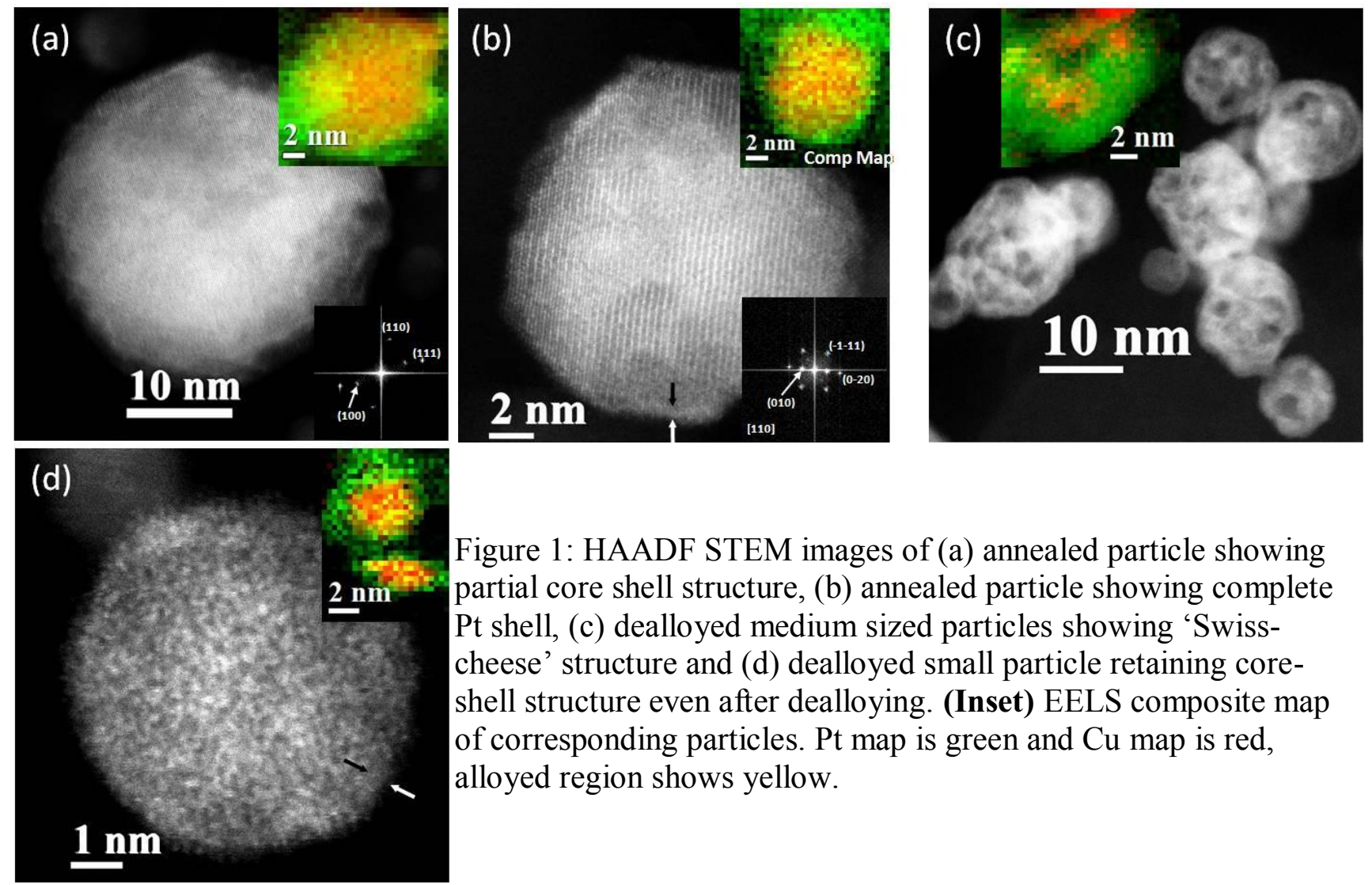

Figure 1: HAADF STEM images of (a) annealed particle showing partial core shell structure, (b) annealed particle showing complete Pt shell, (c) dealloyed medium sized particles showing 'Swisscheese' structure and (d) dealloyed small particle retaining coreshell structure even after dealloying. (Inset) EELS composite map of corresponding particles. Pt map is green and $\mathrm{Cu}$ map is red, alloyed region shows yellow. 